\title{
STRATEGI SISTEM PENANGANAN IKAN TUNA SEGAR YANG BAIK DI KAPAL NELAYAN HAND LINE PPI DONGGALA
}

\section{FRESH TUNA HANDLING STRATEGY ONBOARD HAND LINE FISHING BOATS OPERATING FROM DONGGALA FISHING PORT}

\author{
Normawati K Mboto ${ }^{1}$, Tri Wiji Nurani ${ }^{2}$, Sugeng Hari Wisudo ${ }^{2}$, Mustaruddin ${ }^{2}$ \\ ${ }^{1}$ Program Studi Teknologi Perikanan Laut, Sekolah Pascasarjana \\ Institut Pertanian Bogor \\ ${ }^{2}$ Departemen Sumberdaya Perikanan \\ Fakultas Perikanan dan Kelautan, Institut Pertanian Bogor \\ Korespondensi : k.mboton@yahoo.com
}

\begin{abstract}
There is increasing demand for high quality products at a competitive price. Tuna is a prime commodity with strict quality standards. The research question addressed is whether the tuna handling system used by hand line fishermen operating out of Donggala fishing port (PPI Donggala) is still poor, affecting quality and thus lowering the market value of the fish they catch. The goal of this research was to contribute towards improvements in tuna handling by hand line fishermen from the Donggala fishing port. Thus the main benefit should be an improvement in the quality of the fish landed. The research was carried out during April-May 2014 at the Donggala fishing port in Central Sulawesi. Data were collected through observation and interviews. Data were collected from representative individuals through purposive sampling. Both primary and secondary data were collected. Analysis of data was undertaken with the approach strengths weaknesses opportunities threats (SWOT) analysis it of a training strategies the handling of the good fish on board. Based on of the analysis (SWOT) produced four strategies. The strategy was SO, ST, WO and the strategy W'T. The fourth strategy is good to be applied, but see the position of the system is in a quadrant five (v), then the most appropriate strategy is WO and ST. The combination strategy WO are increased knowledge about the quality and skill handler's tuna fish. Another thing that needs to be done that is the addition of the tools like ring tuna dan killing spike. Ring the functioning to hold the movement of the process of hauling and killing spike to deadly fish tuna. Combination strategy that is making ST it self standard operating prosedure (SOP) handling of good; as well as improving work competence.
\end{abstract}

Keywords: Donggala fishing port, fresh tuna, handling system strategy

\begin{abstract}
ABSTRAK
Mempertahankan kesegaran ikan tuna hasil tangkapan sangat penting demi mendapatkan mutu ikan tuna yang baik sehingga memiliki nilai jual yang tinggi. Kesegaran ikan tuna dapat dipertahankan jika terbentuk suatu strategi sistem penanganan ikan tuna segar yang baik di atas kapal. Tujuan penelitian ini adalah merumuskan suatu strategi untuk membantu meningkatkan mutu ikan tuna hasil tangkapan nelayan hand line karena melihat permasalahan mutu ikan tuna yang dihadapi oleh nelayan hand line PPI Donggala maka diperlukan suatu tindakan untuk mengubah sistem penangaan ikan tuna segar ke arah yang lebih baik. Metode yang digunakan dalam pengambilan data yaitu observasi dan wawancara dengan nelayan, pengumpul serta instansi terkait. Analisis data untuk menyusunan strategi pada sistem penanganan ikan tuna segar skala nelayan hand line dilakukan melalui pendekatan analisis SWOT dengan mengidentifikasi berbagai faktor lingkungan internal dan eksternal secara sistematik dan dilanjutkan dengan merumuskannya. Kemudian dengan membandingkan antara faktor internal yaitu kekuatan (Strengths), dan kelemahan (Weakness) dengan faktor eksternal yaitu peluang (Opportunities) dan ancaman (Threats). Berdasarkan hasil analisis didapatkan beberapa strategi untuk menangani masalah yang dihadapi nelayan hand line yaitu Strategi SO yang meliputi pengaturan sistem operasi penangkapan nelayan hand line dan perbaikan sistem rantai pemasaran ikan tuna segar, strategi ST yang meliputi penerapan sistem manajemen mutu terpadu dan pembuatan SOP penanganan ikan tuna segar diatas kapal hand line, strategi WO yang melip uti penerapan sertifikasi tentang cara penanganan ikan yang baik di atas kapal hand line dan pendampingan oleh teknisi dari instansi terkait kepada nelayan hand line tentang cara penangkapan dan penanganan ikan tuna segar yang baik serta strategi WT yang meliputi penambahan dan perbaikan alat bantu penanganan ikan tuna segar yang lebih baik.
\end{abstract}

Kata kunci: ikan tuna segar, pelabuhan perikanan Donggala, strategi sistem penanganan 


\section{PENDAHULUAN}

Ikan tuna adalah salah satu komoditi unggulan Indonesia dari sektor perikanan karena memiliki nilai ekonomis yang tinggi. Potensi ikan tuna di perairan Indonesia cukup besar dan belum termanfaatkan dengan baik dibeberapa daerah tertentu (Lintang et al. 2012). Salah satu daerah Indonesia yang memiliki potensi ikan tuna yaitu Sulawesi Tengah yang terdapat di empat wilayah pengelolaan perikanan (WPP). Empat WPP tersebut yaitu (1) WPP RI 713 Selat Makassar dan Laut Flores antara lain terdiri dari Kabupaten Tolitoli, Donggala, Kota Palu bersama dengan Kabupaten lainnya yang terletak di Selat Makassar dan Laut Flores; (2) WPP RI 714 Teluk Tolo dan Laut Halmahera terdiri dari Kabupaten Marowali, Marowali Utara, Banggai Laut, Banggai Kepulauan serta Banggai bagian timur; (3) WPP RI 715 Teluk Tomini terdiri dari Kabupaten Parigi Moutong, Poso, Tojo Unauna dan Banggai bagian barat bersama dengan beberapa Kabupaten di wilayah Sulawesi Utara dan Gorontalo; (4) WPP RI 716 terdiri dari Kabupaten Buol dan beberapa Kabupaten yang berada di Gorontalo, Sulawesi Utara dan Kalimantan (Howara \& Lappo 2008). WPP RI 713 Selat Makassar merupakan daerah penangkapan ikan tuna oleh nelayan hand line PPI Donggala. Jenis ikan tuna yang banyak diproduksi oleh nelayan hand line PPI Donggala adalah jenis yellow fin tuna. Ikan tuna yang dihasilkan oleh nelayan hand line memiliki harga jual yang termasuk rendah bila dibandingkan dengan beberapa daerah seperti Bitung, Gorontalo dan Makassar. Mutu ikan tuna yang kurang baik merupakan salah satu faktor yang menyebabkan nilai jual ikan tuna nelayan menjadi rendah.

Aspek penanganan saat ikan tertangkap merupakan hal yang sangat penting untuk diperhatikan, khususnya pada perikanan tuna karena menyangkut bagaimana mendapatkan mutu ikan tuna yang baik. Mutu produk yang baik yang dapat dipertahankan secara konsisten akan meningkatkan kepercayaan konsumen (Olodosu et al. 2011).

Menurut Maulana et al. (2012), aspek mutu merupakan salah satu aspek yang sangat penting dalam memajukan dunia perikanan Indonesia di pasar internasional. Nurani et al. (2011) menambahkan bahwa dalam manajemen kualitas ikan sejak ikan tertangkap sampai pada pemasaran sangat penting untuk dipahami oleh para pelaku terkait baik nelayan, penampung ataupun bagian pemasaran.

Melihat gambaran masalah mutu ikan tuna yang masih kurang baik pada nelayan hand line tuna PPI Donggala maka perlu dilakukan penelitian yang bertujuan untuk membantu mengatasi masalah tersebut. Peneliti mencoba melihat permasalahan dari sistem penanganan tuna di atas kapal "apakah penanganan ikan tuna di atas kapal hand line yang dilakukan oleh nelayan PPI Donggala, sudah merupakan langkah yang tepat dalam usaha menjaga kualitas mutu ikan yang ditangkap serta bagaimana proses penanganan ikan tuna segar pada saat pasca penangkapan yang seharusnya dan faktor apa saja yang bisa mempengaruhi kemunduran mutu ikan tuna tersebut".

Tujuan penelitian ini adalah untuk merumuskan strategi penanganan ikan tuna yang baik di atas kapal hand line nelayan PPI Donggala Sulawesi Tengah.

\section{METODE PENELITIAN}

\section{Lokasi dan waktu penelitian}

Waktu penelitian dilaksanakan selama satu bulan yaitu bulan April sampai dengan bulan Mei 2014. Lokasi yang menjadi objek penelitian yaitu Pangkalan Pendaratan Ikan (PPI) Donggala Sulawesi Tengah (Gambar 1). Metode penelitian yang digunakan adalah observasi, wawancara dan deskriptif kualitatif. Metode observasi dilakukan dengan mengikuti trip penangkapan pada kapal nelayan hand line PPI Donggala.

Observasi dilakukan terhadap unit penangkapan hand line yang beroperasi di Selat Makassar. Metode deskriptif kualitatif digunakan dalam menggambarkan kegiatan penangkapan dan penanganan ikan tuna yang dilakukan oleh nelayan hand line PPI Donggala.

\section{Jenis data dan metode pengumpulan data}

Data yang dikumpulkan dalam penelitian adalah data pimer dan data sekunder. Data primer diperoleh dengan cara purposive sampling. Purposive sampling adalah penentuan sampel berdasarkan keyakinan bahwa sampel tersebut benarbenar mewakili dari total keseluruhan sampel yang ada (Ferdinand et al. 2012). Jumlah data yang diteliti disesuikan dengan kebutuhan penelitian. Data primer yang diambil mencakup nelayan, cara penangkapan, cara penanganan ikan 
tuna di kapal hand line, bahan dan alat yang digunakan untuk penanganan, area kerja penanganan, ukuran kapal, lama waktu penangkapan dan nilai jual ikan tuna. Data sekunder dikumpulkan melalui penelusuran dari berbagai studi pustaka, statistik perikanan, terbitan jurnal dan sumber lainnya yang mendukung dalam penelitian ini.

\section{Metode analisis}

Metode analisis data yang digunakan pada penelitian ini yaitu melakukan pendekatan dengan analisis SWOT dalam merumuskan strategi penanganan tuna yang baik di atas kapal hand line. Prinsip kerja dari analisis SWOT yaitu mengidentifikasi berbagai faktor lingkungan internal dan eksternal secara sistematik dan dilanjutkan dengan merumuskannya. Kemudian dengan membandingkan antara faktor internal yaitu kekuatan (strengths) dan kelemahan (weakness) dengan faktor eksternal yaitu peluang (opportunities) dan ancaman (threats) (Rangkuti 2006).

Proses yang harus dilakukan dalam pembuatan analisis SWOT agar keputusan yang diperoleh lebih tepat perlu melalui tahapan sebagai berikut:

1. Tahap pengumpulan data yaitu pengumpulan data, pengklasifikasian dan pra-analisis faktor eksternal dan internal.

2. Tahap analisis yaitu pembuatan matriks internal dan eksternal dan matriks SWOT.

3. Tahap pengambilan keputusan

Tahapan pembuatan matriks faktor strategi Internal Strategic Factor Summary (ISFS) dan matriks faktor strategi Eksternal Strategic Factors Summary (ESFS) adalah sebagai berikut:

\section{Matriks ISFS}

1. Tentukan faktor-faktor yang menjadi kekuatan dan kelemahan dalam kolom 1.

2. Pemberian bobot masing-masing faktor tersebut pada kolom 2, dengan skala mulai dari 1.00 (sangat penting) sampai 0.00 (tidak penting), berdasarkan pengaruh terhadap posisi strategis sistem. (Semua bobot jumlahnya tidak boleh melebihi skor total 1.00).

3. Hitung rating (dalam kolom 3) untuk masing-masing faktor dengan skala mulai dari 4 (outstanding) sampai dengan 1 (poor), berdasarkan pengaruhnya terhadap sistem. Pemberian nilai rating untuk kekuatan bersifat positif (semakin besar kekuatan semakin besar pula nilai rating yang diberikan), sedangkan untuk kelemahan dilakukan sebaliknya.

4. Selanjutnya dilakukan perkalian bobot dengan rating, untuk menentukan skor terbobot pada masing-masing faktor (kolom 4).

5. Jumlahkan skor pembobotan (pada kolom 4) untuk menentukan kondisi internal sistem. Jika nilai total skor terbobot $>=2.5$ berarti kondisi internal sistem memiliki kekuatan untuk mengatasi situasi (Tabel 1).

\section{Matriks EFAS}

1. Tentukan faktor-faktor yang menjadi peluang dan ancaman (kolom 1)

2. Beri bobot masing-masing faktor dalam kolom 2, mulai dari 1.00 (sangat penting) sampai dengan 0.00 (tidak penting) berdasarkan pengaruhnya terhadap faktor strategis. (Semua bobot jumlahnya tidak boleh melebihi skor total 1.00).

3. Hitung rating (dalam kolom 3) untuk masing-masing faktor dengan skala mulai dari 4 (outstanding) sampai dengan 1 (poor), berdasarkan pengaruhnya terhadap kondisi sistem. Pemberian nilai rating untuk peluang bersifat positif (semakin besar peluang semakin besar pula nilai rating yang diberikan), sedangkan untuk ancaman dilakukan sebaliknya (semakin besar ancaman semakin kecil nilai rating).

4. Selanjutnya dilakukan perkalian bobot dengan rating, untuk menentukan skor terbobot pada masing-masing faktor (kolom 4).

5. Jumlahkan skor pembobotan (pada kolom 4) untuk menentukan kondisi eksternal sistem. Jika total skor terbobot $>=2.5$ berarti sistem mampu merespon kondisi yang ada (Tabel 2). Untuk memperoleh strategi yang tepat maka nilai tersebut diplotkan pada kuadran yang sesuai untuk kemudian dilakukan pembuatan matriks SWOT yang akan menjelaskan alternatif strategi yang dilakukan.

Bedasarkan matriks ISFS dan matriks ESFS, dapat diketahui posisi kuadran kondisi sistem saat ini. Posisi sistem juga 
dapat diketahui dari matriks internaleksternal (IE Matriks).

\section{Matriks IE}

Matriks IE (internal-eksternal) merupakan matriks yang dibuat dengan menggunakan parameter kekuatan internal dan pengaruh eksternal yang dihadapi. Tujuan pembuatan matriks IE adalah untuk memeperoleh posisi sistem saat ini. Matriks IE dapat dilihat pada Tabel 3 .

Langkah selanjutnya setelah membuat matriks IE yaitu membuat matriks SWOT yang menjelaskan berbagai alternatif yang mungkin untuk strategi pengelolaan. Menurut Nurani (2010), penyusunan matriks SWOT merupakan alat pencocokan yang penting untuk mengembangkan empat tipe strategi, di mana pencocokan memerlukan kecermatan dan tidak ada satupun kecocokan terbaik. Dalam matriks ini dapat menggambarkan secara jelas bagaimana peluang dan ancaman eksternal yang dihadapi dapat disesuaikan dengan kekuatan dan kelemahan yang dimiliki.
Matriks ini dapat menghasilkan empat set kemungkinan alternatif strategis (Rangkuti 2006) yaitu:

1. Strategi S-O, strategi ini memanfaatkan seluruh kekuatan untuk mendapatkan dan memanfaatkan peluang sebesarbesarnya.

2. Strategi S-T, strategi ini menggunakan unsur kekuatan untuk mengatasi ancaman.

3. Strategi W-O, strategi ini diterapkan berdasarkan pemanfaatan peluang yang ada dengan meminimalkan unsur kelemahan.

4. Strategi W-T, strategi ini didasarkan pada kegiatan yang bersifat defensiv dan berusaha meminimalkan kelemahan yang ada serta menghindari ancaman.

5. Tahapan selanjutnya adalah pengambilan keputusan, dalam tahapan ini perlu merujuk kembali matriks internal eksternal yang menghasilkan posisi sistem saat ini, dengan melihat posisi kuadran dari sistem sehingga dapat diketahui kombinasi strategi yang tepat (Marimin 2004).

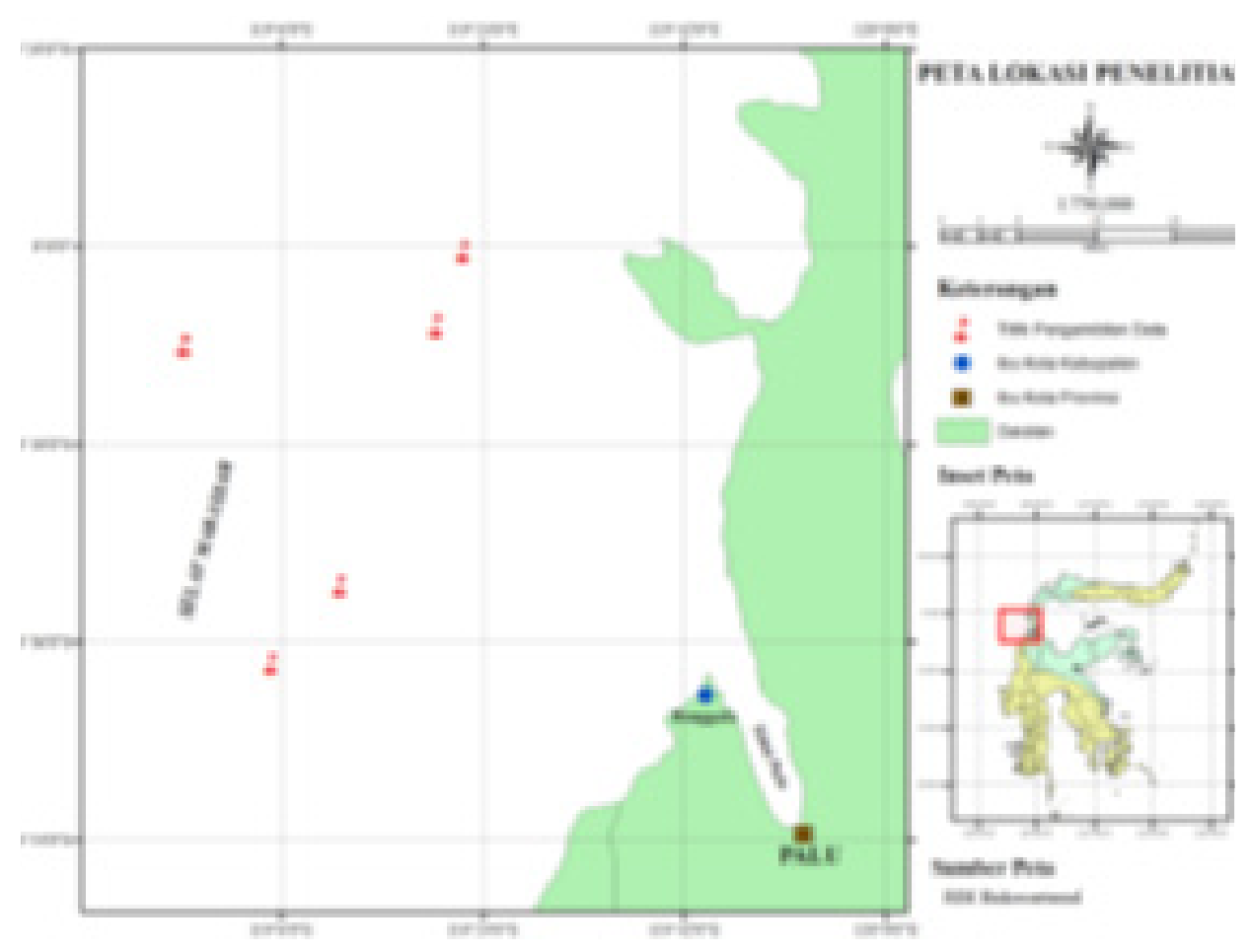

Gambar 1. Lokasi penelitian 
Tabel 1. Matrik evaluasi faktor internal (ISFS)

\begin{tabular}{lllll}
\hline \multicolumn{2}{l}{ Faktor internal } & Bobot & Rating & Bobot*rating \\
\hline Kekuatan & $:$ & & & \\
Kelemahan & $:$ & & & \\
Jumlah & $:$ & & & \\
\hline
\end{tabular}

Tabel 2. Matrik evaluasi faktor eksternal (ESFS)

\begin{tabular}{lllll}
\hline \multicolumn{2}{l}{ Faktor eksternal } & Bobot & Rating & Bobot*rating $^{*}$ \\
\hline Kekuatan & $:$ & & & \\
Kelemahan & $:$ & & & \\
Jumlah & $:$ & & & \\
\hline
\end{tabular}

Tabel 3. Matrik eksternal-internal (sumber: Rangkut1997)

\begin{tabular}{|c|c|c|}
\hline $\begin{array}{c}\text { I } \\
\text { Growth } \\
\text { Konsentrasi melalui } \\
\text { integrasi vertikal } \\
\end{array}$ & $\begin{array}{c}\text { II } \\
\text { Growth } \\
\text { Konsentrasi melalui } \\
\text { integrasi horizontal } \\
\end{array}$ & $\begin{array}{c}\text { III } \\
\text { Rentrechment } \\
\text { turn around }\end{array}$ \\
\hline $\begin{array}{c}\text { IV } \\
\text { Stability } \\
\text { hati-hati }\end{array}$ & $\begin{array}{c}\mathbf{V} \\
\text { Growth } \\
\text { Konsentrasi melalui } \\
\text { intergrasi horizontal }\end{array}$ & $\begin{array}{c}\text { VI } \\
\text { Rentrechment } \\
\text { Captive company } \\
\text { atau divestment }\end{array}$ \\
\hline $\begin{array}{c}\text { VII } \\
\text { Growth } \\
\text { Difersifikasi } \\
\text { konsentrik }\end{array}$ & $\begin{array}{c}\text { VIII } \\
\text { Growth } \\
\text { Difersifikasi } \\
\text { Konsentrik }\end{array}$ & $\begin{array}{c}\text { IX } \\
\text { Rentrechment } \\
\text { Bangkrut atau } \\
\text { likuidasi }\end{array}$ \\
\hline
\end{tabular}

\section{HASIL DAN PEMBAHASAN}

\section{Unit alat tangkap hand line nelayan PPI Donggala}

Berdasarkan hasil wawancara diperkirakan unit alat tangkap hand line PPI Donggala terdiri atas kurang lebih 250 unit akan tetapi yang terdaftar hanya 101 unit. Seratus satu (101) unit alat tangkap hand line tersebut merupakan nelayan tetap di PPI Donggala, sedangkan sisanya adalah nelayan andong yang berasal dari Sulawesi Barat. Alat tangkap yang digunakan oleh nelayan sama seperti dengan alat tangkap hand line pada umumnya. Alat tangkap tersebut terdiri atas penggulung, tali pancing, kili-kili, timah dan mata pancing. Kapal hand line yang digunakan oleh nelayan pada umunya memiliki beban sekitar \pm 12 GT. Satu unit kapal hand line memiliki 6-8 perahu pemancing.
Daerah penangkapan ikan dan hasil tangkapan nelayan hand line PPI Donggala

Daerah penangkapan ikan tuna yang dilakukan oleh nelayan hand line berpusat di perairan Selat Makassar. Penentuan daerah penangkapan ikan tuna dilakukan dengan cara menggunakan alat bantu GPS serta terkadang nelayan menggunakan tanda-tanda alam seperti air berbuih dan kumpulan ikan lumba-lumba.

Hasil tangkapan dari nelayan hand line PPI Donggala yaitu ikan tuna jenis yellow fin. Setiap satu trip penangkapan, nelayan tersebut memperoleh 6-7 ekor tuna. Ukuran bobot tuna yang ditangkap oleh nelayan tersebut pada umumnya sekitar $\pm 40 \mathrm{~kg}$.

Jumlah ikan tuna yang tertangkap di perairan Selat Makassar tidak menentu. Pada musim-musim tertentu jumlah hasil 
tangkapan nelayan meningkat. Hal ini dipengaruhi oleh faktor biologi ikan itu sendiri dan juga dari nelayan tersebut, dimana saat hari-hari besar agama atau hari penting tidak dilakukan operasi penangkapan.

\section{Sistem operasi penangkapan}

Kegiatan operasi penangkapan ikan tuna di perairan Selat Makassar dilakukan setiap hari oleh nelayan. Saat kapal hand line lainnya kembali ke pangkalan sebaliknya sebagian kapal hand line lainnya berangkat menuju daerah penangkapan. Adapun tahap-tahap saat nelayan melakukan penangkapan ikan tuna sebagai berikut.

Persiapan dilakukan nelayan sebelum menuju daerah penangkapan. Perahu pemancing yang akan digunakan diikat di samping kiri dan kanan kapal induk. Jika persiapan sudah selesai barulah nelayan menuju daerah penangkapan sekitar pukul \pm 20:00 WITA. Saat tiba di daerah penangkapan nelayan langsung beristrahat dan akan memulai aktivitas pemancingan pada pukul 05:00 WITA.

Teknik operasi penangkapan ikan tuna yang dilakukan oleh nelayan terbagi dalam tiga waktu sebagaimana tertera pada Gambar 2. Aktivitas penangkapan di mulai dengan kapten kapal utama akan menyebar perahu-perahu pemancing. Tiap satu perahu pemancing terdiri oleh satu orang pemancing (nelayan). Kapten kapal yang berada di kapal utama akan menunggu nelayan pemancing selama operasi penangkapan dilakukan. Jika salah satu nelayan pemancing mendapatkan ikan tuna, maka kapal utama tersebut akan merapat ke perahu pemancing tersebut untuk membantu proses hauling.

Proses hauling dilakukan di kapal utama karena perahu pemancing yang digunakan sangat kecil. Saat proses hauling dilakukan waktu yang digunakan cukup lama biasanya sekitar \pm 40 menit. Lamanya proses hauling ini disebabkan karena masih menggunakan tenaga manusia.

\section{Sistem penanganan ikan tuna segar}

Nelayan hand line PPI Donggala memiliki cara penanganan sendiri berdasarkan atas pengalaman. Aktivitas penanganan ikan tuna yang dilakukan oleh nelayan di atas kapal utama dapat dilihat pada Gambar 12 dengan uraian adalah sebagai berikut:
1. Pembersihan dek kapal: Pada saat proses hauling sedang berlangsung, salah satu nelayan membersihkan dek kapal untuk untuk persiapan peletakan ikan tuna. Pembersihan dek kapal dilakukan dengan menggunakan air laut yang diambil dengan menggunakan ember lalu disiramkan ke dek kapal sampai di anggap bersih.

2. Persiapan alat bantu penanganan: Selain membersihkan dek kapal, pada saat itu juga nelayan tersebut telah menyiapkan alat bantu penanganan untuk mengangkat dan mematikan ikan tuna.

3. Ikan tuna ditahan dengan ganco: Saat ikan sudah berada di permukaan tepat di samping kapal, ikan tersebut langsung di ganco pada bagian insang dan pada bagian mulut.

4. Mematikan ikan: Bersamaan saat ikan tuna ditahan dengan ganco di permukaan tepat di samping kapal, ikan tersebut langsung dimatikan dengan menggunakan kayu pemukul.

5. Pelepasan mata pancing: Setelah ikan tuna dimatikan, nelayan melepaskan mata pancing yang masih melekat di mulut ikan tuna. Pelepasan mata pancing dilakukan nelayan dengan tangannya langsung (tanpa menggunakan alat bantu).

6. Ikan tuna dinaikkan ke atas kapal: nelayan menaikkan ikan tuna di atas kapal dengan menggunakan ganco sebagai alat bantu. Ikan tuna yang sudah diganco diangkat dan diletakkan di dek kapal.

7. Penyiangan insang, isi perut dan sirip: Dilakukan dengan menggunakan pisau yang terbuat dari bahan mudah berkarat.

8. Pencucian ikan tuna: Setelah penyiangan insang dan isi perut, barulah pencucian ikan tuna dilakukan. Pencucian dilakukan dengan menggunakan air laut yang diambil dengan menggunakan ember. Ikan disiram dengan air laut sampai ikan tersebut dianggap bersih.

9. Pendinginan awal: Ikan tuna diletakkan pada bagian atas wadah penyimpanan dalam keadaan belum tersusun rapi. Setelah itu nelayan kembali melakukan aktivitas pemancingan dengan menggunakan perahu pemancing.

10. Penyimpanan dalam wadah pendingin: Setelah waktu istrahat pemancingan tiba, barulah ikan tuna tersebut disusun dengan rapi dalam wadah pendingin. 
Penyusunan ikan dilakukan dengan cara berlapis-lapis yaitu es kemudian ikan tuna dan seterusnya pada bagian atas dilapisi dengan es.

11. Pembersihan alat dan area kerja: Setelah selesai proses penanganan ikan tuna dilakukan, nelayan membersihkan area kerja dan semua alat yang digunakan dengan air laut dan menyimpannya kembali ke tempatnya.

12. Pembongkaran ikan tuna: Setelah tiba di pangkalan, nelayan langsung melakukan pembongkaran. Pembongkaran dilakukan sekitar pukul \pm 16 :00 WITA.

Ikan tuna segar yang dihasilkan oleh nelayan berdasarkan proses penanganan pada Gambar 3 sebagian besar memiliki nilai jual rendah. Berdasarkan hasil wawancara dengan pengumpul dan pihak terkait dari instansi DKP, nilai jual yang rendah ini pada umumnya dikarenakan oleh mutu hasil tangkapan yang kurang baik.

\section{Analisis faktor internal dan eksternal sistem penanganan ikan tuna segar nelayan hand line PPI Donggala}

Berdasarkan hasil pengklasifikasian pra-analisis faktor internal (kekuatan dan kelemahan) dan faktor eksternal (peluang dan ancaman) sistem penanganan ikan yang sangat berpengaruh terhadap penurunan mutu hasil tangkapan hand line nelayan PPI Donggala yaitu sebagai berikut.

\section{Kekuatan}

1. Hand line merupakan alat tangkap ikan tuna yang tepat untuk ikan tuna. Alat tangkap pancing khususnya hand line merupakan alat tangkap yang tepat untuk ikan tuna dibandingkan dengan alat tangkap lain karena tidak menyebabkan cacat fisik pada ikan seperti alat tangkap purse seine.

2. Memiliki kapal utama yang berfungsi sebagai penampung. Nelayan hand line memiliki dua kapal, satu sebagai perahu pemancing, sedangkan satu kapalnya sebagai kapal yang digunakan saat proses hauling dan sebagai kapal penampug hasil tangkapan. Adanya kapal ini sangat memudahkan nelayan, karena nelayan tidak harus kembali ke pangkalan saat mendapatkan ikan tuna. Ikan tersebut akan disimpan pada kapal utama tersebut, setelah itu kembali melakukan pemancingan.

3. Memiliki banyak perahu pemancing.
Perahu pemancing yang dimiliki oleh nelayan yaitu terdiri atas 7-8 perahu. Banyaknya perahu pemancing ini sangat membantu nelayan dalam meningkatkan produksi hasil tangkapaan tuna.

4. Tersedianya umpan untuk memancing ikan tuna. Umpan yang digunakan oleh nelayan hand line untuk memancing ikan tuna tersedia di pangkalan. Umpan tersebut diperoleh dari nelayan purse seine. Tersedianya umpan di pangkalan sangat membantu nelayan hand line dalam melakukan pemancingan ikan tuna.

5. Umur nelayan yang masih produktif. Berdasarkan pengamatan dan wawancara pada nelayan hand line PPI Donggala, nelayan hand line pada umumnya memiliki kisaran umur antara 20-40 tahun, dimana merupakan umur yang produktif dalam melakukan aktivitas.

\section{Kelemahan}

1. Pengetahuan nelayan yang masih minim. Pengetahuan yang baik sangat berperan penting dalam meningkatkan mutu hasil tangkapan. Jika nelayan memiliki pengetahuan tentang cara mempertahankan kesegaran hasil tangkapan maka kecil kemungkinan terjadi kesalahan. Pengetahuan nelayan masih sangat minim hal ini dibuktikan dengan mutu hasil tangkapan yang kurang baik. Selain itu pada umumnya nelayan hanya menyelesaikan pendidikan di tingkat sekolah dasar.

2. Keterampilan menangani ikan tuna yang masih kurang baik. Keterampilan penanganan sangat diperlukan dalam dalam menghasilkan mutu ikan tuna yang baik. Keterampilan nelayan dalam menangani ikan tuna masih sangat minim hal ini dibuktikan dengan masih banyaknya kekeliruan dalam melakukan penanganan ikan tuna di atas kapal.

3. Cara mematikan ikan tuna masih kurang tepat. Pengamatan yang dilakukan ikan tuna hasil tangkapan dimatikan dengan cara dipukul menggunakan kayu pemukul. Seperti yang telah diuraikan pada bab sebelumnya bahwa penggunaan kayu pemukul untuk mematikan ikan tuna masih kurang tepat. Hal ini dikarenakan ikan yang mati dipukul akan mati dalam keadaan lemas sehingga cepat terjadinya proses penanganan.

4. Proses hauling yang cukup lama. 
Proses hauling yang lama juga sangat mempercepat proses penurunan mutu saat ikan mati. Hal ini disebabkan sebelum ikan mati, ikan tersebut kelelahan karena melakukan perlawanan saat hauling.

5. Suhu penyimpanan tidak terkontrol. Pengontrolan suhu penyimpanan ikan merupakan hal yang penting dalam mempertahan kesegaran ikan. Kenaikan suhu penyimpanan akan menyebabkan meningkatnya aktivitas bakteri yang menyebabkan terjadinya proses penurunan mutu. Pengontrolan suhu tidak dilakukan oleh nelayan hand line selama penyimpanan hasil tangkapan.

Berdasarkan matriks ISFS pada Tabel 4 dapat diketahui bahwa dalam sistem penanaganan ikan tuna segar oleh nelayan hand line memiliki skor ISFS 2.68 (<2.50). Hal ini menunjukkan bahwa kondisi internal sistem masih memilki kekuatan untuk mengatasi situasi atau masalah yang dihadapi nelayan tersebut.

\section{Faktor eksternal (peluang dan ancaman)}

\section{Peluang}

1. Memiliki tempat pendaratan ikan hasil tangkapan. Adanya tempat pendaratan ikan sangat membantu nelayan. Hal ini dikarenakan saat membongkar hasil tangkapan, nelayan hand line tidak lagi kebingungan mencari tempat untuk mendaratkan hasil tangkapannya.

2. Tersedianya pabrik es di PPI Donggala. PPI Donggala memiliki pabrik es yang dapat memenuhi kebutuhan es nelayan hand line untuk penanganan ikan. Dengan demikian nelayan tidak lagi mencari es di tempat yang jauh dari pangkalan.

3. Tersedianya pasar ikan tuna. Pasar ikan tuna yang dimaksudkan adalah adanya pembeli yang menetap di pangkalan untuk membeli hasil tangkapan nelayan. Adanya buyer tersebut, memudahkan nelayan dalam memasarkan hasil tangkapannya.

4. Potensi ikan tuna yang masih tersedia. Berdasarkan pembagian Wilayah Pengelolaan Perikanan Republik Indonesaia (WPP-RI) salah satu WPP RI yang dekat dengan PPI Donggala yaitu WPP 713 (Selat Makassar). WPP ini merupakan daerah penangkapan bagi nelayan hand line PPI tersebut yang masih memiliki potensi ikan tuna dengan syarat dimanfaatkan secara berkelanjutan.

5. Adanya pembeli yang menetap di pangkalan. Adanya penampung yang menetap di pangkalan tersebut sangat membantu nelayan karena nelayan tidak harus pergi jauh untuk menjual ikan hasil tangkapan.

\section{Ancaman}

1. Belum adanya tenaga ahli dari instansi terkait. Tenaga ahli yang dimaksudkan adalah tenaga teknis yang memiliki kompetensi dibidang pengendalian mutu ikan tuna itu sendiri sehingga dapat mengawasi dan memberikan pendampingan langsung selama proses penanganan ikan tuna di kapal agar mutu ikan tuna yang dihasilkan baik.

2. Tidak adanya standar resmi yang digunakan dalam penanganan ikan tuna. Berdasarkan pengamatan langsung dan wawancara yang dilakukan dengan nelayan, penanganan ikan tuna di lakukan atas dasar pengalamannya sendiri. Sementara itu dari penampung hanya memberikan arahan bahwa ikan tuna yang dihasilkan harus utuh dan tidak cacat tanpa ada prosedur atau tata cara penanganan ikan tuna yang diberikan kepada nelayan.

3. Instansi terkait lebih mengutamakan nelayan purse seine. Hasildariwawancara dengan nelayan serta pihak instansi bagian penangkapan menyatakan bahwa kebijakan yang dibuat oleh DKP Provinsi lebih mengarah kepada pengadaan kapal purse seine dengan alasan ingin meningkatkan produksi hasil tangkapan. Ini dibuktikan dengan adanya kapal-kapal purse seine yang dilengkapi dengan wadah penampungan dan alat bantu penanganan lainnya dengan keadaan baik.

4. Tidak adanya pelatihan khusus penanganan ikan tuna yang baik pada nelayan hand line. Hasil wawancara dengan pihak terkait, pelatihan khusus penanganan pada nelayan hand line belum dilakukan oleh instansi terkait. Pelatihan penanganan hanya lebih mengarah kepada penampung yang mengolah tuna loin dengan tujuan untuk meningkatkan pasar ikan tuna yang ada di Palu dan Donggala. Selain itu kegiatan lebih mengarah ke penyuluhan tentang budidaya rumput laut.

5. Tingkat pendidikan nelayan hand line 
pada umunya masih sangat rendah. Rendahnya tingkat pendidikan yang dimiliki sangat berpengaruh terhadap pengetahuan yang dimiliki, pengetahuan tersebut sangat penting dalam meningkatkan kualitas penanganan hasil tangkapan.

Berdasarkan matriks ESFS sistem penanganan ikan tuna segar ditingkat nelayan hand line PPI Donggala pada Tabel 4 dengan skor 2.82 Artinya bahwa ancaman dari sistem penanganan tuna yang dihadapi oleh nelayan hand line PPI Donggala, masih mampu diatasi dengan memanfaatkan peluang yang ada.

\section{Analisis penentuan posisi sistem penanaganan ikan tuna nelayan hand line PPI Donggala}

Langkah selanjutnya yaitu membuat matriks IE SWOT dengan menggunakan nilai ISFS dan ESFS (Gambar 4).

Berdasarkan matriks IE, dapat diketahui posisi sistem penanganan hasil tangkapan nelayan hand line di PPI Donggala yaitu berada pada sel lima (V). Berdasarkan Rangkuti (1997), berada pada sel ini menunjukkan sistem berada pada posisi growth (konsentrasi melalui integrasi horizontal) dan stability (hati-hati). Artinya bahwa posisi sistem penanganan mutu sudah dilakukan oleh nelayan selama ini, namun perlu upaya perbaikan-perbaikan dalam meningkatkan mutu ikan tuna hasil tangkapan dengan meminimalkan kelemahan dan mengatasi ancaman yang dihadapi, sehingga mutu ikan tuna yang didaratkan memiliki kualitas terbaik serta dapat diterima di pasar global. Upaya perbaikan tersebut dapat dilakukan dengan menggunakan strategi WO dan ST (Tabel 6).

Berdasarkan matriks SWOT pada Tabel 6, penggunaan strategi WO dapat dilakukan dengan cara yaitu (1) penyuluhan tentang mutu ikan; (2) pelatihan penanganan ikan tuna yang baik; (3) penggunaan ring tuna saat dilakukan hauling; dan (4) penggunaan killing spike untuk mematikan ikan tuna. Kemudian strategi ST itu sendiri dapat dilakukan dengan cara (1) pembuatan Standard Operating Procedure (SOP) penanganan yang baik; serta (2) peningkatan kompetensi kerja.

\section{Perumusan strategi sistem penanganan ikan tuna yang baik ditingkat nelayan hand line PPI Donggala}

Hasil dari analisis SWOT sistem penanganan ikan tuna segar pada nelayan hand line PPI Donggala dihasilkan empat kombinasi strategi SO, strategi ST, strategi WO dan strategi WT.

Kombinasi strategi SO menghasilkan pengadaan mesin penghancur es dan pengoptimalan pemanfaatan tuna di perairan Selat Makassar. Mesin penghancur es dan pengoptimalan pemanfaatan tuna di perairan Selat Makassar. Mesin penghancur berfungsi untuk menghaluskan es balok yang digunakan oleh nelayan saat akan menyimpan ikan tuna dalam wadah penyimpanan. Es yang dihancurkan dengan mesin penghancur es memiliki partikel yang lebih halus dan memiliki ukuran partikel yang sama. Halusnya ukuran partikel es yang dihasilkan akan mempercepat proses pendinginan ikan tuna dalam wadah penyimpanan. Hal ini dikarenakan pada saat dalam wadah, es tersebut tersusun rapat dengan ikan tuna, sehingga tidak terdapat celah atau rongga udara yang dapat mempercepat proses pencairan es yang memicu terjadinya kenaikan suhu penyimpanan.

Pengoptimalan pemanfaatan tuna di perairan Selat Makassar. Potensi ikan tuna yang tersedia di perairan Selat Makassar masih dapat dimanfaatkan secara berkelanjutan demi memenuhi kebutuhan pasar (Kantun et al. 2014). Namun demikian pemanfaatan ikan tuna perlu diperhatikan juga cara penangkapannya, agar mutu ikan tuna hasil tangkapan tetap terjaga. Terjaganya mutu hasil tangkapan dapat meningkatkan kepercayaan konsumen serta dapat menentukan nilai jual.

Kombinasi strategi ST yang menghasilkan pembuatan SOP penanganan yang baik dan peningkatan kompetensi kerja. SOP adalah serangkaian instruksi tertulis yang diberlakukan mengenai berbagai proses tentang bagaimana, kapan harus dilakukan dan oleh siapa yang melakukan, dengan tujuan untuk meminimalkan kesalahan (Sani 2012). SOP penanganan ikan yang baik ini berguna sebagai acuan atau pedoman bagi nelayan saat melakukan proses penanganan ikan tuna di atas kapal hand line. Hal ini dikarenakan nelayan bisa melihat prosedur dalam melakukan penanganan ikan tuna yang baik di kapal hand line, sehingga kecil kemungkinan terjadinya kesalahan teknis yang bisa menyebabkan cacat atau penurunan mutu. SOP ini juga akan membantu dalam hal pengawasan dan pengendalian mutu, 
sehingga mutu hasil tangkapan konsisten sesuai dengan tuntutan konsumen atau buyer. Sebagaimana dijelaskan oleh Junais et al. (2014) bahwa pengawasan dan pendalian mutu produk yang dilakukan dengan baik sejak dari awal produksi sampai distribusi akan dapat meningkatkan kepercayaan konsumen dan keamanan produk.

Peningkatan kompetensi kerja ini bertujuan untuk meningkatkan kemampuan kerja nelayan secara khusus dengan cara mengambil satu nelayan per satu unit kapal hand line. Nelayan ini akan dibimbing dan didampingi oleh tenaga ahli sampai betulbetul paham tentang mutu ikan dan cara penanganan yang baik. Tujuannya yaitu agar setiap satu unit kapal hand line memiliki satu orang yang memiliki kompetensi dalam menangani ikan tuna sekaligus dapat mengawasi dan memberitahukan kepada yang lainnya saat melakukan penanganan ikan tuna di atas kapal. Jika strategi ini dilakukan dan berjalan dengan baik maka kecil kemungkinan untuk menghasilkan mutu ikan yang kurang baik.

Kombinasi strategi WO menghasilkan penyuluhan tentang mutu ikan tuna yang baik pada nelayan hand line, pelatihan penanganan ikan tuna yang baik, perlu adanya ring tuna dan killing spike.

Penyuluhan merupakan suatu proses pembelajaran yang ditujukan kepada sekelompok orang dengan maksud pencapaian tujuan (Hubeis 2007). Penyuluhan tentang mutu ikan tuna kepada nelayan bertujuan untuk meningkatkan pengetahuan nelayan hand line tentang bagaimana mempertahankan kesegaran ikan, agar ikan tuna tersebut memiliki mutu yang baik. Penyuluhan dapat dilakukan oleh instansi terkait dalam hal ini DKP Provinsi Sulawesi Tengah.

Pelatihan penanganan ikan tuna yang baik pada nelayan hand line juga sangat penting. Pelatihan penanganan ikan tuna termasuk dalam pelatihan kerja, yang mana pelatihan kerja merupakan suatu wadah bagi seseorang untuk mendapatkan pelajaran dengan tujuan meningkatkan keterampilan yang dimiliki (Zuana et al. 2014). Pelatihan dapat dilakukan oleh tenaga ahli dari instansi terkait dengan sungguh-sungguh dalam memberikan bimbingan sehingga keterampilan nelayan dapat ditingkatkan. Meningkatnya keterampilan nelayan dalam menangani ikan tuna hasil tangkapan, akan menekan seringnya terjadi kesalahan teknis sehingga ikan tuna yang dihasilkan memiliki mutu yang baik.
Strategi berikutnya dari kombinasi WO yaitu perlu adanya ring tuna. Ring tuna digunakan untuk menahan gerakan ikan saat hauling. Tujuannya adalah agar ikan tuna tidak kelelahan. Hal ini dilakukan mengingat ikan tuna yang mati dalam keadaan lemas lebih cepat mengalami proses penurunan mutu (WWF 2011 \& BPPI 2014).

Ring tuna dioperasikan setelah ikan sasaran terasa terkait/tersangkut pada mata pancing, kemudian ring tuna segera dipasang dan diluncurkan melalui tali pancing untuk mengurangi atau menyelubungi ikan tangkapan. Penggunaan ring tuna diharapkan dapat mengatasi permasalahan dalam penanganan pasca penangkapan tuna dengan alat tangkap hand line. Ring tuna tersebut bisa mengurangi kelelahan fisik ikan akibat adanya perlawanan saat hauling, sehingga mampu menjaga ikan dalam keadaan pre rigor dan rigor mortis lebih lama. Jika hal ini dapat dilakukan maka mutu ikan tuna hasil tangkapan akan lebih baik.

Kombinasi terakhir dari strategi WO yaitu perlu adanya killing spike yaitu paku yang digunakan untuk mematikan ikan dengan cara ditusuk. Penggunaan killing spike sangat mudah diterapkan oleh nelayan hand line PPI Donggala jika diberikan contoh. Berdasarkan DJPT (2014), penggunaan killing spike untuk mematikan ikan tuna yaitu saat ikan sudah berada di atas kapal, bila ikan masih berontak maka ikan tersebut perlu ditenangkan terlebih dahulu. Ikan tuna ditenangkan dengan cara menutup mata ikan tersebut dengan tangan (menggunakan sarung tangan) sampai ikan tersebut tidak berontak. Langkah selanjutnya menusuk pusat syaraf otak ikan tuna dari belakang mata dengan menggunakan killing spike sedalam 5-10 cm sehingga ikan tersebut langsung mati.

Kombinasi strategi WT menghasilkan pembentukan tim pengawas pengendalian mutu dari intansi terkait dan intervensi instansi terkait dalam penambahan dan pengadaan alat bantu penanganan ikan tuna yang baik. Pembentukan tim pengawas ini dimaksudkan agar dapat melihat atau mengawasi secara rutin aktivitas pembongkaran dan penjualan ikan tuna hasil tangkapan nelayan ke pihak pembeli. Strategi ini bertujuan agar didapatkan informasi tentang mutu ikan tuna hasil tangkapan nelayan secara akurat, sehingga team ahli bisa langsung membantu dengan memberikan arahan tentang kesalahan- 
kesalahan yang selama ini dilakukan nelayan. Adanya arahan-arahan tersebut, akan membuat nelayan lebih berhati-hati dalam melakukan penanganan ikan tuna di atas kapal. Sebagaimana dijelaskan oleh Ardansyah \& Wasilawati (2014) bahwa pengawasan merupakan suatu kegiatan yang dilakukan oleh suatu tim atau perorangan dengan maksud mengukur apa yang sedang atau sudah dilaksanakan dengan kriteria norma standar atau rencana-rencana yang ditetapkan dengan tujuan agar menjadi lebih baik.

Strategi kedua dari WT yaitu intervensi instansi terkait dalam penambahan dan pengadaan alat bantu penanganan ikan tuna yang baik. Intervensi yang dimaksudkan adalah campur tangan/bantuan dari instansi terkait dalam hal pengadaan alat bantu penanganan yang baik pada nelayan hand line. Hal ini dilakukan dengan harapan nelayan bisa menyadari bahwa betapa pentingnya menjaga mutu ikan hasil tangkapan. Pengadaan alat bantu penanganan ini sangat penting karena mengingat alat bantu penanganan yang dimiliki oleh nelayan hand line masih kurang baik. Salah satu alat bantu yang sangat penting yaitu alat pengontrol suhu. DJPT (2014) menyatakan bahwa kapal penangkap yang sekaligus menampung hasil tangkapan lebih dari 24 jam, harus memiliki wadah yang terjaga kebersihannya serta melakukan pengontrolan suhu, dimana suhu penyimpanan tidak bisa melebihi $0{ }^{\circ} \mathrm{C}$ setelah 16 jam. Selain itu alat bantu penanganan lainnya pun harus digantikan dengan yang lebih baik, agar penanganan hasil tangkapan yang dilakukan oleh nelayan betul-betul menjamin bahwa peralatan yang digunakan tidak menulari ikan tuna yang ditangani.

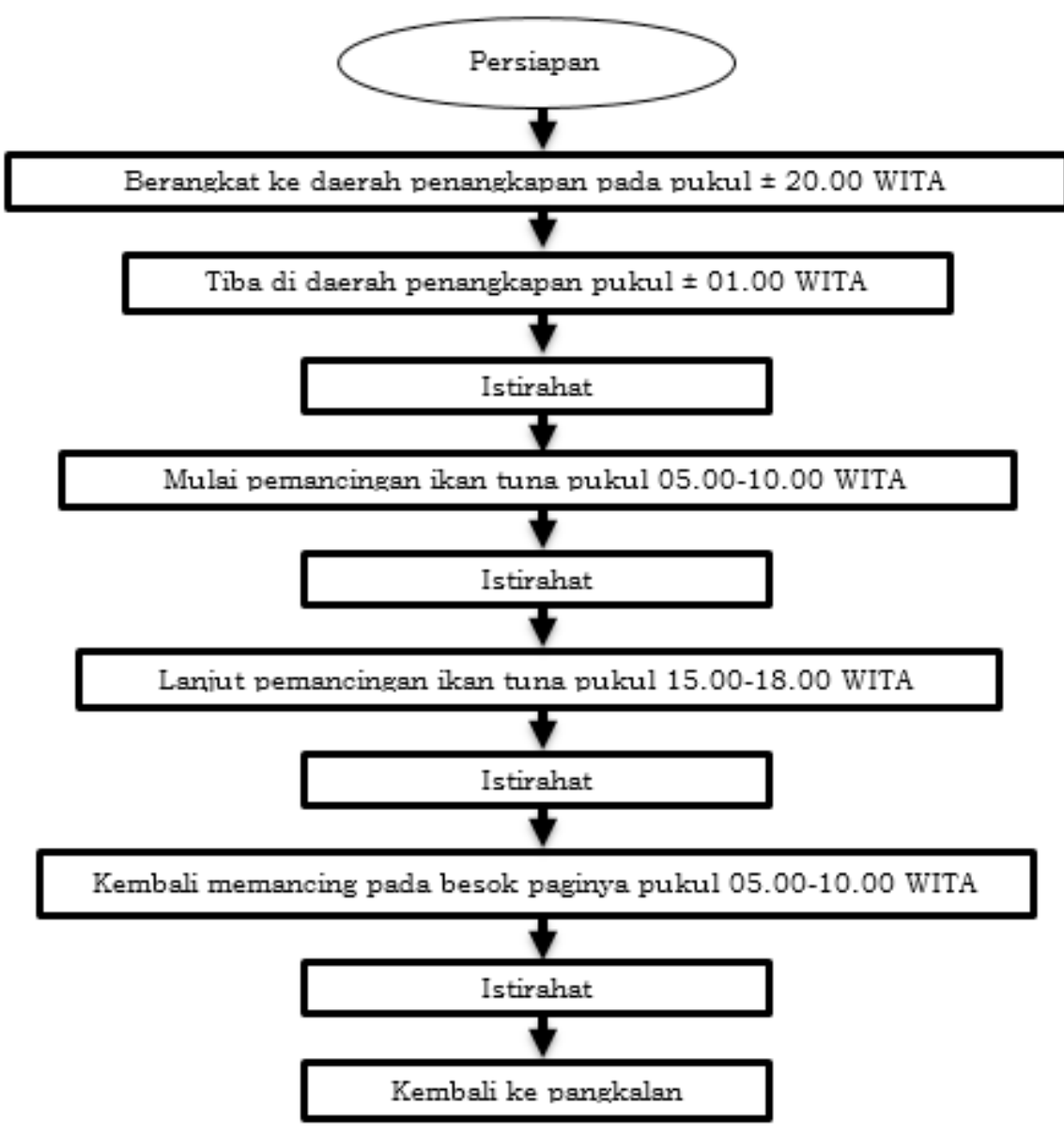

Gambar 2. Bagan alir sistem operasi penangkapan ikan tuna oleh nelayan hand line PPI Donggala 


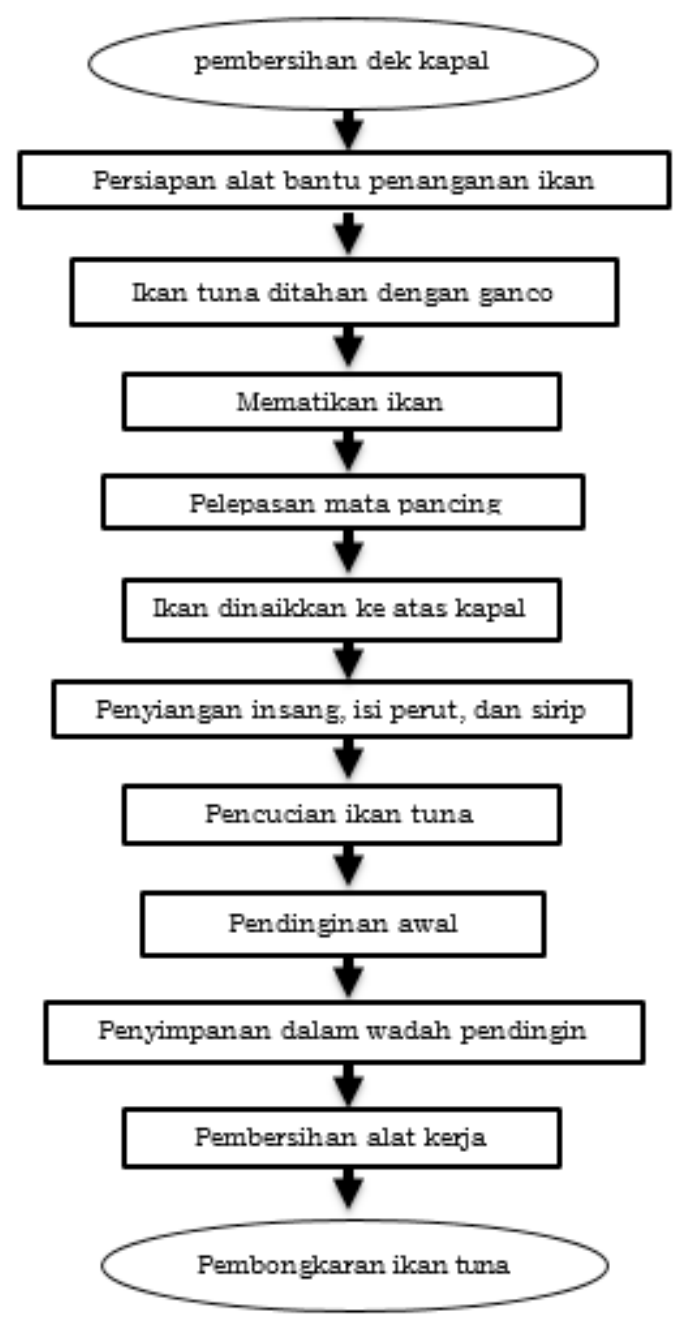

Gambar 3. Bagan alir sistem penanganan ikan tuna oleh nelayan hand line PPI Donggala yang dilakukan di kapal utama

Tabel 4. Matriks ISFS sistem penanganan ikan tuna nelayan hand line

\begin{tabular}{lccc}
\hline \multicolumn{1}{c}{ Unsur SWOT } & Bobot & Rating & Skor \\
\hline Kekuatan & & & \\
Hand line merupakan alat tangkap ikan tuna yang tepat & 0.26 & 4 & 1.04 \\
Memiliki kapal utama yang berfungsi sebagai penampung & 0.12 & 4 & 0.48 \\
Memiliki banyak perahu pemancing & 0.07 & 4 & 0.28 \\
Tersedianya umpan untuk memancing ikan tuna & 0.03 & 3 & 0.09 \\
Umur nelayan yang masih produktif & 0.03 & 3 & 0.09 \\
& & & \\
Kelemahan & & & \\
Pengetahuan nelayan yang masih minim & 0.15 & 1 & 0.15 \\
Keterampilan menangani ikan tuna yang masih kurang baik & 0.13 & 1 & 0.13 \\
Cara mematikan ikan tuna masih kurang tepat & 0.07 & 2 & 0.14 \\
Proses hauling yang cukup lama & 0.07 & 2 & 0.14 \\
Suhu penyimpanan tidak terkontrol & 0.07 & 2 & 0.14 \\
Total & 1 & & 2.68 \\
\hline
\end{tabular}


Tabel 5. Matriks ESFS sistem penanganan ikan tuna nelayan hand line

\begin{tabular}{|c|c|c|c|}
\hline Unsur SWOT & Bobot & Rating & Skor \\
\hline \multicolumn{4}{|l|}{ Peluang } \\
\hline Memiliki tempat pendaratan ikan hasil tangkapan & 0.25 & 4 & 1 \\
\hline Tersedianya pabrik es di PPI Donggala & 0.15 & 4 & 0.60 \\
\hline Tersedianya pasar ikan tuna & 0.10 & 4 & 0.40 \\
\hline Potensi ikan tuna yang masih tersedia & 0.06 & 3 & 0.18 \\
\hline Adanya pembeli yang menetap di pangkalan & 0.04 & 3 & 0.12 \\
\hline \multicolumn{4}{|l|}{ Ancaman } \\
\hline Belum ada tenaga ahli dari instansi terkaitt & 0.16 & 1 & 0.16 \\
\hline $\begin{array}{l}\text { Tidak adanya standar resmi yang digunakan hal pengawasan } \\
\text { mutu }\end{array}$ & 0.12 & 1 & 0.12 \\
\hline Instansi terkait lebih mengutamakan nelayan purse seine & 0.05 & 2 & 0.10 \\
\hline $\begin{array}{l}\text { Tidak adanya pelatihan khusus penanganan ikan tuna yang } \\
\text { baik }\end{array}$ & 0.05 & 2 & 0.10 \\
\hline $\begin{array}{l}\text { Tingkat pendidikan nelayan hand line pada umumnya sangat } \\
\text { rendah }\end{array}$ & 0.02 & 2 & 0.04 \\
\hline Total & 1 & & 2.82 \\
\hline
\end{tabular}

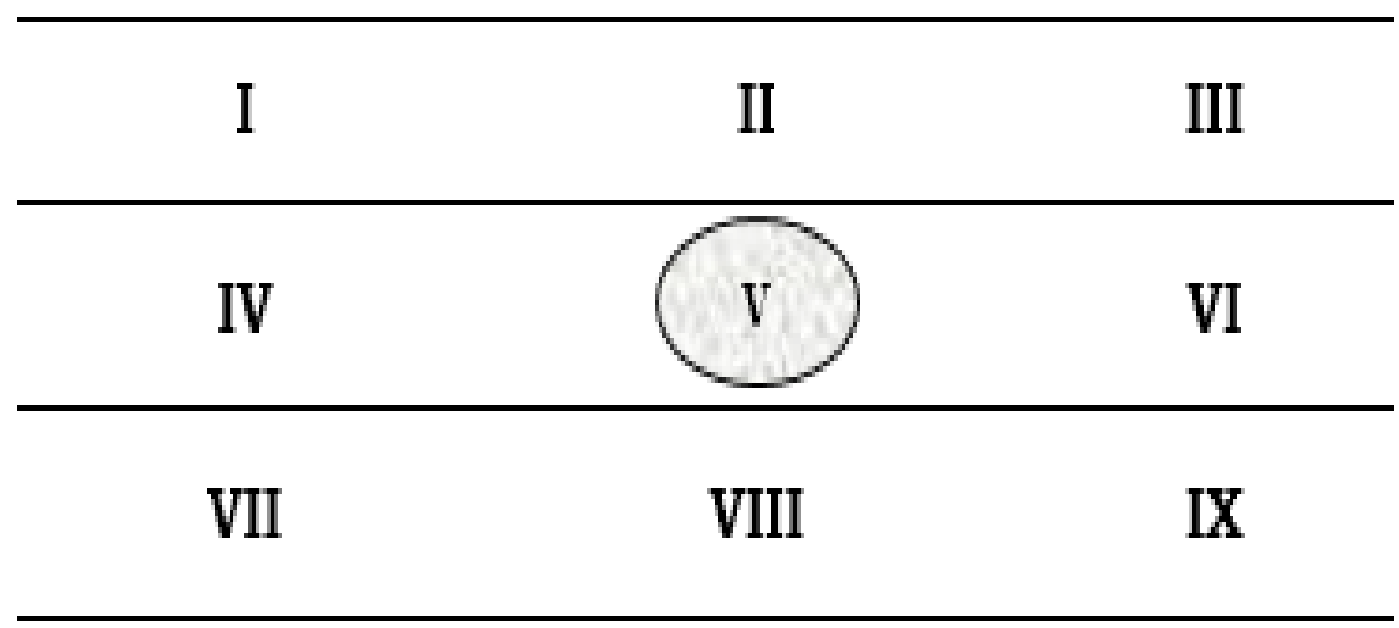

Gambar 4. Matriks IE (internal-eksternal) sistem penanganan ikan tuna 
Tabel 6. Matriks SWOT sistem penanganan ikan tuna nelayan hand line

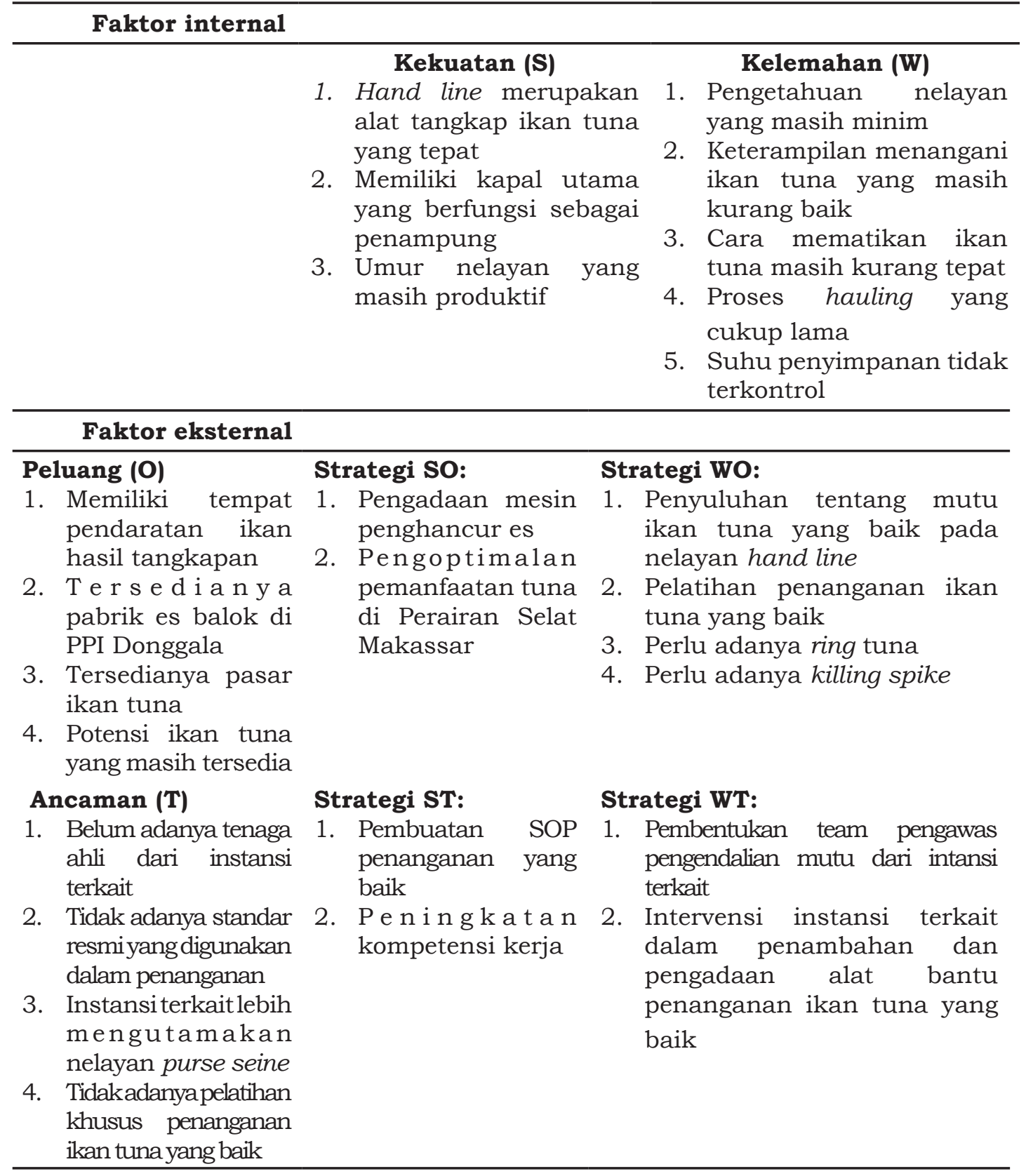

\section{KESIMPULAN DAN SARAN}

\section{Kesimpulan}

Mengatasi keseluruhan masalah yang dihadapi oleh nelayan hand line tersebut, langkah penanggulangan yang paling tepat untuk dilakukan yaitu menggunakan hasil kombinasi strategi WO dan ST yaitu peningkatan keterampilan dan pengetahuan nelayan. Karena jika keterampilan dan pengetahuan nelayan baik, maka nelayan akan memahami bagaimana proses penanganan yang baik sehingga kesegaran hasil tangkapan dapat dipertahankan sampai ke tangan konsumen, pembuatan SOP penanganan yang baik serta peningkatan kompetensi kerja dan penambahan alat bantu penanganan seperti ring tuna dan killing spike. Penggunaan ring tuna sangat membantu untuk menahan gerakan ikan tuna saat hauling sehingga ikan tuna tidak kelelahan yang dapat memicu cepatnya terjadi proses penurunan mutu, selain itu dapat mengefisienkan waktu hauling. Terakhir yaitu penggunaan killing spike untuk mematikan ikan tuna. Proses mematikan ikan dengan cara menggunakan killing spike jauh lebih efektif daripada kayu pemukul seperti yang 
digunakan nelayan hand line selama ini. Hal ini dikarenakan saat menggunakan killing spike untuk mematikan ikan dengan menusuk tepat pada otak ikan, ikan tuna tersebut langsung mati sehingga mutu ikan dapat dipertahankan.

\section{Saran}

Saran yang dapat disampaikan terkait dengan "Analisis Permasalahan Penanganan Ikan Tuna di atas Kapal Hand Line PPI Donggala" adalah sebagai berikut:

1. Penelitian lanjutan tentang kandungan bakteri patogen pada hasil tangkapan nelayan hand line PPI Donggala.

2. Penelitian lain mengenai supply chain serta pengembangan perikanan tuna nelayan hand line PPI Donggala. Hal ini bertujuan agar dapat di ketahui permasalahan lain yang mempengaruhi harga jual hasil tangkapan nelayan hand line PPI Donggala.

3. Mencontoh perikanan tuna hand line di Bandarneira, karena nelayan di sana mempunyai SOP yang baku sehingga mutu tuna hasil tangkapannya mencapai mutu tuna segar untuk sashimi yang diekspor ke Jepang dengan harga yang tinggi.

\section{DAFTAR PUSTAKA}

Ardansyah, Wasilawati. 2014. Pengawasan kerja, dan kinerja pegawai Badan Pusat Statistik Kabupaten Lampung Tengah. Jurnal JMK. VOL (16)2:153162.

[BBPPI] Balai Besar Pengembangan Penangkapan Ikan. 2014. Seri Alat Tangkap Ikan, Kontruksi, dan Keunggulan Bubuh Kubah. Semarang (ID): BBPPI.

[DJPT] Direktorat Jendral Perikanan Perikanan Tangkap. 2014. Jaminan Mutu dan Keamanan Pangan di Kapal Perikanan. Jakarta (ID): DJPT.

[DJPT] Direktorat Jendral Perikanan Perikanan Tangkap. 2014. Tata Kelola Yang Baik Pada Sektor Perikanan dan Kelautan. Jakarta (ID): DJPT.

Ferdinand F, Maulina I, Rosidah. 2012. Analisis permintaan ikan lele dumbo (Clarias gariepinus) konsumsi di Kecamatan Losarang Kabupaten Indramayu. Jurnal Perikanan dan Kelautan . VOL (3)4:93-98.

Howara D, Laapo A. 2008. Analisis determinasi usaha perikanan tangkap nelayan di Kabupaten Tojo Unauna. Jurnal Agroland Universitas Tadulako. VOL (15)4:302-308.

Hubeis AVS. 2007. Motivasi, kepuasan kerja dan produktivitas penyuluhan pertanian lapangan di Kabupaten Sukabumi. Jurnal Penyuluhan Institut Pertanian Bogor. VOL (3)2:90-99.

Junais, Brasit N, Latief R. 2014. Kajian strategi pengawasan dan pengedalian mutu produk ebi furay PT. Bogatama Marinusa. Journal of Fisheries Resources Utilization Management and Technology Universitas Diponegoro. VOL (2)5:15-20.

Kantun W, Mallawa A, Rapi NL. 2014. Struktur ukuran dan jumlah tangkapan tuna Madidihang (Thunnus albacares) menurut waktu penangkapan dan kedalaman di perairan Majene Selat Makassar. Jurnal Saintek Perikanan Universitas Hasanuddin Makassar. VOL (9)2:3948.

Lintang CJ, Labaro IL, Teller ATL. 2012. Kajian musim penangkapan ikan tuna dengan alat tangkap hand line di Laut Maluku. Jurnal Ilmu dan Teknologi Perikanan Tangkap Universitas Samratulangi. VOL (1) 1:6-9.

Marimin. 2004. Pengambilan Keputusan Kriteria Majemuk. Jakarta (ID): Grasindo.

Nurani TW. 2010. Model Pengelolaan Perikanan Suatu Kajian Pendekatan Sistem. Bogor (ID): Institut Pertanian Bogor.

Nurani TW, Astarini JE, Nareswari M. 2011. Sistem penyediaan dan pengendalian kualitas produk ikan segar di Hypermarket. Jurnal Pengelolaan Hasil Perikanan Indonesia Institut Pertanian Bogor. VOL (14)1:56-62.

Olodosu, Ajayai RN, George FOA, Obasa SO, Bankole MO. 2011. Bacterial load, composition and succession in the African catfish, Clarias gariepinus held at ambient temperatures. Journal Researcher University Ota Ogun State Nigeria. VOL (3)7:67-73.

Rangkuti F. 1997. Analisis SWOT Teknik Membedah Kasus Bisni-Reorientasi Konsep Perencanaan Strategis untuk Menghadapi Abad 21. Jakarta (ID): Gramedia Pustaka Utama.

Rangkuti F. 2006. Analisis SWOT Teknik Membedah Kasus Bisnis. Jakarta (ID): Gramedia Pustaka Utama.

Sani. 2012. Standar operasional prosedur 
(SOP) pelayanan perizinan mendirikan bangunan (IMB) di Kota Pontianak. Jurnal EKSOS. VOL (8)3:156-163.

[WWF] World Wide Fund for Nature. 2011. Panduan Perikanan Skala Kecil Penangkapan dan Penangnan Tuna. Jakarta (ID): WWF-Indonesia.
Zuana CI, Swasto B, Susilo H. 2014. Pengaruh pelatihan kerja dan lingkungan kerja karyawan terhadap prestasi kerja karyawan (Studi pada Karyawan PT Jamsostek (Persero). Jurnal Administrasi Bisnis Universitas Brawijaya Malang. VOL (7)1:1-9. 